\title{
ИССЛЕДОВАНИЯ РОССИИ/СССР И СТРАН ВОСТОЧНОЙ ЕВРОПЫ ПОСЛЕ ХОЛОДНОЙ ВОЙНЫ: НОВОЕ ЛИЦО дИСЦИПЛИНЫ*
}

В 2018 году Американская ассоциация восточноевропейских и евразийских исследований (ASEEES) отмечала свой 70-летний юбилей. Это был хороший повод подвести итоги и вспомнить прошлое. Л. Грэм, участник первого съезда Ассоциации в 1964 г. (которая называлась тогда иначе - Американская ассоциация содействия славянским исследованиям - AAASS), сравнил его программу с 50-й сессией 2018 г. Цифры говорят сами за себя: 21 докладчик против нескольких сотен докладов и презентаций в год юбилея. «Мы только начинали это длинное и плодотворное путешествие», результатом которого станет множество секций, с докладами по специализированным темам, подкрепленными архивными источниками, с участниками из разных стран, что было немыслимо в разгар холодной войны, - пишет Л. Грэм, выдающийся историк советской науки (Graham 12). Воспоминания нескольких президентов Ассоциации не столь оптимистичны. Все они посвящены борьбе за выживание, которая началась после окончания холодной войны, когда дисциплина утратила свой особый статус «борца с коммунизмом» и,

ОльГА ВлАдимИРОВНА БольшАКОВА, кандидат исторических наук - Институт научной информации по общественным наукам РАН, ИНИОН; e-mail: jkmuf16@gmail.com; ORCID: https://orcid.org/ 0000-0002-9032-3115.

Olga Bolshakova, dr nauk historycznych - Instytut Informacji Naukowej o Naukach Społecznych Rosyjskiej Akademii Nauk, INION; e-mail: jkmuf16@gmail.com; ORCID: https:// orcid.org/ 0000-0002-9032-3115.

Olga Bolshakova, PhD in history - Institute of Scientific Information for Social Sciences, Russian Academy of Sciences (INION), Moscow, Russia; e-mail: jkmuf16@ gmail.com; ORCID: https://orcid.org/ 0000-0002-9032-3115.

* Статья подготовлена при поддержке РФФИ, проект №20-59-00001/20 «Современное зарубежное историческое белорусоведение: эволюция методологических подходов и оценок». 
со-ответственно, лишилась щедрого финансирования. Ей пришлось на общих основаниях интегрироваться в научное сообщество в новых условиях деидеологизации и изменившихся геополитических реалий (Большакова 15-16).

Кризисные явления, наблюдавшиеся в начале 1990-х годов в исследованиях России/СССР, стран Восточной Европы и бывшего советского пространства (для краткости обозначаемых «Russian and East European Studies» - REES), носили как институциональный, так и методологический характер. Третий, не менее важный компонент - эмоциональнопсихологический. В тот период всеобщей открытости он сыграл безусловно позитивную роль. Достаточно узкое по профессиональным меркам и очень пестрое в дисциплинарном отношении научное сообщество зарубежных русистов/славистов почувствовало не только свою сопричастность к «великим событиям», но и поддержку «простых людей».

Как вспоминала Марианна Клодин, занимавшая в 1995 г. пост президента Ассоциации, круг людей, с которыми она профессионально контактировала, расширился тогда чрезвычайно. Это было, по ее словам, «незабываемое время» - полное надежд, оптимизма и энергии. В то же время всех беспокоили «тревожные вопросы»: как происходящие изменения отразятся на нашей работе? Как нам теперь определять нашу область исследований на новой карте мира? Утратят ли правительство и фонды интерес к изучаемому нами региону? Иссякнет ли финансирование? И не иссякнет ли интерес к русскому и другим славянским языкам у американцев, которые никогда не были особенно расположены к изучению иностранных языков? (Choldin 5). Ответы на эти вопросы сохранили свою актуальность и сегодня. Борьба за выживание, начавшаяся после холодной войны, продолжается, и ее основным инструментом является перестройка дисциплины.

За прошедшие тридцать лет REES кардинально изменились. Что стоит за этой почти дежурной фразой? В небольшой статье невозможно раскрыть ее содержание во всей полноте, попытаемся лишь очертить основные тенденции и показать новые черты в облике дисциплины, возникшие за это время.

В период кризиса 1990-х годов мощная инфраструктура, созданная в годы холодной войны, с одной стороны, стабилизировала весьма неод- 
нородную дисциплину REES, с другой - давала возможность перестраиваться в соответствии с новыми условиями деидеологизации (О структуре исследовательских и образовательных институций в англоязычных странах, включая библиотечные ресурсы, см.: Меньковский). Перестройка шла неравномерно и не так быстро, что отразилось, в частности, в переименовании соответствующих структур и программ. Нередко оно сводилось к простому добавлению приставки «пост» (проблемы посткоммунизма), но там, где содержалось указание на регион, который прежде определялся политически («страны социализма»), изменения оказались более существенными. В обиход входят такие идеологически нейтральные термины, как «Центрально-Восточная Европа» и «Евразия», что должно было соответствовать новой «воображаемой географии» и одновременно расширить охват исследований (Большакова 16-17). Процесс переименований до сих пор не закончен - совсем недавно слово «Eurasian» добавила в свое название кафедра славянских языков и литератур в университете Канзаса, с той же целью расширения географического охвата (теперь на кафедре преподаются турецкий и персидские языки) и одновременно для преодоления европоцентризма (Kokobobo 17-18).

В 1990-е годы происходили и другие изменения. В частности, много споров тогда велось вокруг советологии - есть ли у нее будущее или она должна «упокоиться с миром» (см.: Beyond Soviet studies). Однако жизнь расставляла всё по своим местам: в тот период многие из советологов переквалифицировались в «транзитологов», занявшись анализом перспектив перехода СССР и стран бывшего социалистического лагеря на «западные» рельсы. Как следствие особенно востребованными на какое-то время стали экономические темы.

Составной частью кризиса 1990-х годов являлось движение за ликвидацию региональных исследований как «наследия холодной войны» (Engerman 334). Противопоставление регионального подхода узкоспециализированному дисциплинарному надолго определило характер споров о будущем REES. И всё же их перестройка велась не столь прямолинейно, как хотелось бы тем, кто подчеркивал анахронизм этой дисциплины. Действительно, в ходе реорганизации научных программ и систем грантовой поддержки регион как центральная категория, вокруг которой строилось финансирование науки и образования, начал утрачивать приоритет. Предпочтение стали отдавать крупным темам и проблемам: демократия и развитие, этничность и национализм, 
миграции. Однако регион остается важной категорией, и при присуждении грантов учитывается комплекс составляющих. Например, в 2000-е годы стали охотно финансировать исследования Средней Азии, которые фокусировались на изучении этничности и империализма. Здесь явно играла роль совокупность критериев: недостаток специалистов по региону, политические запросы дня (Большакова 39-40).

Несомненно, политическая повестка продолжала и продолжает оказывать влияние на состояние REES, но важнейшим дестабилизирующим фактором является падение интереса к России (и региону в целом) на Западе - и в обществе, и в правительственных структурах. Это отражается как на финансировании, так и на количестве студентов, желающих специализироваться по этому обширному региону; их поток сокращается, соответственно уменьшается количество позиций на соответствующих кафедрах, так же как и количество читающихся курсов.

Ухудшение общей ситуации коснулось и американской Ассоциации славистов: если в 1990 г. в ней состояло 3889 членов, а у ее органа журнала «Slavic review» было 4990 подписчиков, то в 2001 г. в нее входило 2997 человек, а подписка упала на 20\%. По воспоминаниям тогдашнего президента Ассоциации, историка Уильяма Розенберга, была предпринята «перестройка», нацеленная на финансовую оптимизацию и повышение привлекательности для потенциальных членов. В частности, журнал «Slavic review» повысил свой авторитет благодаря вхождению в Social Science Index, а оцифрованный архив номеров был включен в базу данных JSTOR (Rosenberg 8-9). Слоганы «оцифровка», «интернационализация», «перегруппировка» оставались актуальными и для 2010-х годов (Grant 10-11). В перестройке этой организации решались те же проблемы, которые стояли перед REES в целом: облегчение доступа к источникам, упрощение коммуникации и формирование интернационального сообщества исследователей России и стран постсоветского пространства. К настоящему времени многое достигнуто на этом пути: в последние годы число членов Ассоциации варьирует вокруг показателя 3500 чел., среди них немало (примерно одна треть) ученых из разных стран, и не только из Северной Америки (Park, «2019 Executive Director Report» 7).

Специалисты в области REES и руководство Ассоциации много делают для того, чтобы дисциплина развивалась и дальше (стоит упомянуть о запущенной недавно «The Future of the Field Campaign»), но общий контекст остается сложным. 
Особенно тяжелым для REES в CША стало решение администрации Обамы урезать финансирование программ по международному образованию в среднем наполовину (в результате которого особенно сильно пострадали исследования Евразии) (Adams 2-3). Была сначала закрыта, а потом восстановлена, но только в половинном объеме знаменитая программа грантовой поддержки Title VIII. Борьба за финансирование велась специалистами в области российских и восточноевропейских исследований на самых разных уровнях и в разных сферах. В результате в американских СМИ лишь укрепилось мнение, что REES находятся в глубоком кризисе, что побудило Ассоциацию подготовить в 2015 г. доклад об их состоянии в США (Gerber). Выводы его автора Теодора Гербера призваны опровергнуть это мнение, они довольно оптимистичны, хотя приведенный им статистический материал далеко не всегда их подтверждает.

В докладе Гербера приводятся данные интервью с вашингтонскими чиновниками, а также с персоналом и участниками учебных программ в университетах-лидерах. В центре их внимания - Россия, как бывший соперник США в противостоянии времен холодной войны. Чиновники как один отметили, что после ее окончания поток специалистов, поступающих на государственную службу, постоянно сокращался. Талантливая амбициозная молодежь стала предпочитать России более важные для внешней политики США регионы - Китай, Средний Восток, Индию. После 11 сентября повысился интерес к арабским странам. Однако внутренняя политика России продолжает оставаться для США актуальной, и здесь специалисты из аналитических центров и ученые не согласны с государственными чиновниками. Они полагают, что хотя экспертов по России и стало меньше, их знания - глубже, а учитывая количество выходцев из региона в этих структурах, уровень информированности и аналитики сегодня куда выше, чем в годы холодной войны. Все интервьюированные отрицали наличие каких-то предубеждений против России у молодых специалистов, однако почти все указали на тенденциозность СМИ, упрощенность трактовок и на склонность привлекать экспертов старшего поколения, чьи взгляды далеко не репрезентативны для экспертного сообщества в целом. Большинство указывали, что сокращение финансирования и закрытие таких программ, как TVI и TVIII, может иметь далеко идущие негативные последствия (Gerber 44-45). 
Им вторят историки и гуманитарии - представители научных дисциплин, изначально занимавших в REES ведущие позиции. По их оценкам, процветают те, кто имеет значительную частную поддержку, - такие институции, как Гарримановский институт в Колумбийском университете или Дэвисовский центр в Гарварде, при том, что подавляющее большинство университетов опирается на федеральные ресурсы. Кроме того, существует проблема получения работы после защиты диссертации - возможности здесь очень невелики (Gerber 4-5). Три четверти активных исследователей среди респондентов Гербера получили в 2010-2014 гг. финансовую поддержку, чаще всего в виде грантов от федерального правительства, причем по этому показателю (а также по размерам грантов) специалисты в области социальных наук опережают других (Gerber 27). Слависты и историки менее активны, чем специалисты по социальным наукам, когда дело касается поездок в страну изучения, участия в научных обменах и преподавательской деятельности (Gerber 31-35).

В то же время Гербер фиксирует спад и кризис именно в социальных науках, указывая на сокращение в 2010-2014 гг. количества защищенных докторских диссертаций $(\mathrm{PhD})$. Между тем, столь краткий временной промежуток не является репрезентативным для оценки ситуации. Следует брать больший интервал, что позволит на материале диссертаций проследить траекторию развития науки, выявить актуальные темы и подходы (а также институции, в которых велась исследовательская работа). Кроме того, диссертации - это потенциал науки, который реализуется в серьезных монографиях. Оговоримся сразу, что подсчеты по защищенным диссертациям можно произвести сугубо приблизительно, поскольку все больше работ использует сравнительную перспективу, рассматривая параллельно несколько регионов. Не менее приблизительны и подсчеты в рамках одной дисциплины.

Прежде всего посмотрим на количественный показатель по REES в целом за 2000-2015 гг. в англоязычных странах. В США и Канаде он крайне нестабилен, варьируя от года к году в пределах между 212 и 388 представленными к защите докторскими диссертациями. При более широком временном охвате фиксируются два пика: во второй половине 1990-х годов и в 2005-2007 гг. Начиная с 2014 г. заметен серьезный спад; однако данные, ежегодно публикуемые в журнале Slavic Review, явно неполны (вероятно, из-за особенностей заданных условий поиска). В Великобритании и Ирландии, по данным базы UTREES, при всех 
флуктуациях, имеется стабильный прирост (в 2000 г. - 147, в 2015 206) (Walker 4). Но в любом случае можно заключить, что ежегодно в англоязычных странах защищается приблизительно четыре сотни диссертаций по REES.

Конечно, если распределить эти сотни по отдельным регионам и странам изучения, по предметам и темам исследований, цифры будут совсем другими, варьируя от единицы до нескольких десятков ежегодно. Максимальное количество диссертаций защищается по русской истории и литературе, причем в Великобритании преобладает история, в США и Канаде - литература (в 2000 г. 67 и 20 в Великобритании, в США - 26 и 34 соответственно) (Walker 9; Thurston, «Doctoral Dissertations 2001»). Естественно, среди регионов Россия как тема исследования статистически лидирует, однако есть и другие традиционно крупные исследовательские кластеры - например, польских исследований; довольно сильно после распада СССР выдвинулась вперед украинистика.

В региональном отношении наблюдается весьма отчетливая динамика. В США и Канаде в 1999 г. доля диссертаций по собственно России - ее истории, культуре, языку - составляла чуть более половины, около 20\% пришлось на диссертации по бывшим советским республикам; по странам Восточной Европы - приблизительно треть (Thurston, «Doctoral Dissertations» 2000). В 2013 г. картина изменилась: на Россию приходится около четверти всех диссертаций, столько же - по бывшим советским республикам. По странам Восточной Европы - половина (Thurston, «Doctoral Dissertations 2013» 970-985). Эта тенденция в общем и целом подтверждается данными базы UTREES по Великобритании. В 2000 г. Россия (и РСФСР) как предмет исследования составляла одну треть всех защищенных диссертаций, к 2015 г. соотношение составило 1:3 (Walker 7).

Наряду с повышением веса восточноевропейских исследований и снижением внимания к России возникает интерес к регионам, которыми раньше почти не занимались. Наиболее яркий пример - Албания, но тут, по мнению автора доклада UTREES, играет роль грантовая поддержка (Walker 8).

Интересно посмотреть и на количество институций, в которых защищались диссертации по REES. Данные по Северной Америке и здесь крайне неравномерны. В 2000 г. было подготовлено 212 диссертаций в 92 университетах, в 2005 - 353 в 123, в 2013 - 273 в 104 (Thurston, 
«Doctoral Dissertations 2000»; «Doctoral Dissertations 2005»; «Doctoral Dissertations 2013»). Достаточно сильно выросло количество институций, в которых защищаются диссертации по REES, на Британских островах - почти в 3 раза, но произошло это в 1990-е годы, а в 2000-2015 гг. рост был незначителен (55 и 67 соответственно). Причем львиная доля работ готовится в крупных центрах, традиционно занимавшихся славистическими исследованиями - Оксфорде, Кембридже, Университетском колледже Лондона, Бирмингеме, Глазго (Walker 5-6).

В США наблюдается та же тенденция. В докладе Гербера составлен рейтинг учебных и исследовательских программ по России. В своих оценках респонденты были достаточно единодушны, поместив в первую тройку университеты Беркли, Гарвардский и Колумбийский. За ними следуют Принстон, Висконсин, Мичиган и Индиана. При этом в дисциплинарном отношении места распределились следующим образом: Беркли опережает всех по истории и славистике, Гарвард - по социальным наукам, Колумбийский университет лидирует в изучении России и стран Восточной Европы, незначительно от него отстают Индиана и Джорджтаун (Gerber 37).

В то же время, в оценке исследователей старшего поколения, по сравнению с временами холодной войны снизилось качество подготовки специалистов: сократилось количество предлагающихся курсов, гораздо хуже стали готовить по языку. По замечанию бывшего президента Ассоциации славистов Э. Мицкевич, грантовые программы все чаще просят в качестве результата исследования представить практические рекомендации для политики, что ввергает историков и филологов в ступор (Mickiewicz 3). Ведь даже в пору жесткого идеологического противостояния им удавалось «делать науку», всячески избегая политики (Engerman).

Тогда считалось, что между теми, кто изучает «текущий момент», ассоциирующийся с политикой, и «настоящими учеными» пролегает глубокий водораздел. В сегодняшней ситуации это противопоставление утрачивает свою значимость, как и противопоставление регионального подхода специализированному дисциплинарному. Конечно, продолжают выходить работы и защищаться диссертации того сорта, которые в период холодной войны ассоциировались с «советологией», а в конечном итоге с политической ангажированностью. Но так называемый «текущий момент» рассматривается сегодня на куда более высоком уровне. В частности, политология (political science) как научная дисциплина 
серьезно развивалась в 1990-е годы, обогатившись новыми методологическими подходами и обратившись к широким сравнительно-теоретическим обобщениям.

Кроме того, само понятие «текущего момента» чрезвычайно расширилось. С открытием для иностранцев доступа в архивы в странах изучения, с расширением возможностей для ведения полевой работы главной темой для изучения стало общество. В центре внимания молодых исследователей - образование и здравоохранение, гендерная структура, психология, с особым вниманием к травматическим социальным ситуациям, массовые коммуникации и многое другое. Совершенно новая тема, возникшая в 1990-е годы - этнические меньшинства, включая проблемы миграции и иммиграции (где заметную долю составляют исследования эмигрировавших в США из России евреев, в рамках бурно развивающейся сегодня иудаики) (Thurston, «Doctoral Dissertations 2013» 970-985).

Пожалуй, главная особенность сегодняшних REES - изобилие проблематики и научных дисциплин, в рамках которых готовятся диссертации. Помимо истории, литературы и лингвистики, социологии, политики, права, экономики и бизнеса, это этнология, социальная и культурная антропология, гендерные исследования, экология, исследования религии, искусствоведение, музыковедение, история театра и кино. С одной стороны, все эти дисциплины получили глубокое развитие, с другой - происходит определенная ассимиляция наук, которая совсем непохожа на междисциплинарность послевоенных региональных исследований с их цивилизационным подходом. Сегодня имеет смысл говорить о мультидисциплинарности, поскольку исследователи используют широкий спектр методологических подходов из разных наук.

Так, многие антропологи работают в архивах, а историки используют материалы интервью, и те и другие опираются в своих исследованиях на методы лингвистического, литературоведческого, искусствоведческого анализа. Да и сама история к настоящему времени серьезно изменилась, став гуманитарной наукой, и с возвышением так называемой «культурной истории» с начала 2000 -х годов наблюдается своего рода «конвергенция» истории и литературоведения. В то же время и литературоведы все чаще рассматривают литературу в ее связи с социальностью. Из диссертаций середины 2000-х гг. по литературе выросли монографии, которые внесли серьезный вклад в наше понимание именно истории России. В частности, «Мы современные люди» Аниндиты Банерджи предлагает глубокий анализ идей о научно-техническом про- 
грессе, циркулировавших в России на заре XX в.; «Написано кровью» Линн Патык исследует историю терроризма, опираясь на известный тезис о связи литературы с жизнью (Banerjee; Patyk).

При этом история продолжает сохранять свое ведущее положение в REES. На ежегодном съезде ASEEES в 2011 г. тематика докладов распределилась следующим образом: история - 36\%, литература и культура - 29, социальные науки - 15; остальные $20 \%$ поделили между собой гендерные исследования, иудаика, изучение религии и др. (Park, 2011 17).

Еще одна новая черта REES - обилие выходцев из стран бывшего СССР и Восточной Европы, защищающих диссертации в США и Великобритании. Судить об этом можно лишь поверхностно, по фамилиям и именам. В 2000 г. в Великобритании их доля составляла 24\%, а в 2010 и 2015 - 45 и 44\% соответственно (Walker 10). Это можно интерпретировать как одно из проявлений процесса интеграции и интернационализации дисциплины. Безусловно важным цементирующим фактором является английский язык, на котором публикуются специалисты из других стран.

К настоящему времени споры о правомерности регионального подхода утихли, и регион становится тем «зонтиком», под которым возможно собрать крайне разнообразный «букет» из дисциплин и тем, представляющих сегодня интерес для исследователей. Стоит проиллюстрировать это на примере региона, который не так давно появился на карте REES - Беларуси. Интерес к нему стабильно растет, а теперь, когда Беларусь не выходит из списка топовых заголовков в новостях, можно предсказать, что он только усилится.

Заметный интерес к этой бывшей советской республике проявился уже в середине 1990-х годов, когда активно занимались проблемой Чернобыля. Он неизменно присутствовал в начале 2000-х и явно возрос в 2010-е годы. Защищенные в 2010-2019 гг. диссертации (их около 30) заслуживают специального внимания, тем более что ряд из них подготовлен в таких авторитетных институциях, как Гарвард и Принстон, Кембридж и Лондонский университет. Примерно половина диссертантов явно не англосаксонского происхождения: есть и белорусские, и русские, и польские фамилии и имена. Преобладающей дисциплиной является история - в основном XX в., хотя присутствуют и политология, социальная и культурная антропология, литературоведение, гендерные и женские исследования, религиоведение и др. 
Распределяются диссертации по следующим тематическим кластерам: чернобыльская катастрофа и ее последствия; Вторая мировая война и Холокост; белорусская национальная идентичность; проблемы постсоветской Беларуси. Большинство из этих работ демонстрируют если не новизну и смелость выводов, то актуальность и новизну современных методологических подходов.

В диссертации Александра Новикова чернобыльская катастрофа рассматривается в плоскости формирования и эволюции экологических дискурсов в Беларуси в 1985-2014 гг. (Novikau). Этим она разительно отличается от работ 1990-х годов, где главную роль играла фактология.

Тема белорусской национальной идентичности обрела актуальность также в 1990-е годы, когда проблемы этнонационализма стали крайне популярны в мировой науке. Диссертанты, во-первых, предлагают новые ее ракурсы, во-вторых - раскрывают не известные ранее страницы истории белорусского национализма.

С начала 2000-х годов история Холокоста на территории Белоруссии становится предметом научного анализа, и диссертации по этой теме основываются на архивных источниках и материалах устной истории. Многие из них пересекают границы, как хронологические - водораздел 1917 г. - (Grachova), так и государственные, рассматривая польско-русский/советский фронтир как единое пространство - borderlands (Joyce; Koerber). Установочной стала для них известная книга американского антрополога Кейт Браун о «кресах» - территории на русско-польском пограничье, наиболее пострадавшей в мировых войнах (Brown). В настоящее время транснациональный поход к истории Восточной Европы $\mathrm{XX}$ в. развивается достаточно активно, и диссертации, посвященные Беларуси, лишь подкрепляют эту тенденцию. Они вполне вписываются в новый облик дисциплины REES, характерными чертами которой являются открытость и креативность.

После окончания холодной войны REES прошли большой путь, превратившись из «изучения потенциального врага» в современную, живую, активно развивающуюся область знания. Вполне закономерным стало сокращение удельного веса России как предмета изучения в пользу стран Восточной Европы - при одновременном расширении географического и тематического охвата. Столь же закономерно и всё более широкое участие в этих исследованиях выходцев из разных стран, что придает прежде исключительно «западной» дисциплине REES фактически глобальный характер. 


\section{БИБЛИОГРАФИЯ}

Adams, Laura L. «The Crisis of U.S. Funding for Area Studies». NewsNet: News of the Association for Slavic, East European, and Eurasian studies, vol. 53, no. 2, 2013, pp.1-3.

Banerjee, Anindita. We Modern People: Science Fiction and the Making of Russian Modernity. Wesleyan UP, 2012.

Beyond Soviet Studies, edited by Daniel Orlovsky. The Woodrow Wilson Center Press, 1995.

Bolshakova, Olga V. Poverkh bar'yerov: Amerikanskaya rusistika posle kholodnoy voyny. INION, 2013 [Большакова, Ольга В. Поверх барьеров: Американская русистика после холодной войны. ИНИОН, 2013].

Brown, Kate. A Biography of No Place: From Ethnic Borderland to Soviet Heartland. Harvard UP, 2004.

Choldin, Marianna T. «Celebrating ASEEES: Reflections on the 1990s». NewsNet: News of the Association for Slavic, East European, and Eurasian studies, vol. 57, no. 5, 2018, pp. 5-6.

Engerman, David. Know your enemy: The Rise and Fall of America's Soviet Experts. Oxford UP, 2009.

Gerber, Theodore P. «The State of Russian Studies in the United States: An Assessment by the Association for Slavic, East European, and Eurasian studies (ASEEES). July 2015». Association for Slavic, East European, and Eurasian studies, www.aseees.org/sites/default/ files/downloads/FINAL-ASEEES-assessment-report.pdf. Accessed 19 Dec. 2020.

Grachova, Sofiya. Pathologies of Civility: Jews, Health, Race and Citizenship in the Russian Empire and the Bolshevik State, 1830-1930. PhD dissertation. Harvard, ProQuest Dissertations Publishing, 2014.

Graham, Loren R. «Celebrating ASEEES: Reflections on the Inaugural Convention». NewsNet: News of the Association for Slavic, East European, and Eurasian studies, vol. 57, no. 4, 2018, p. 12.

Grant, Bruce. «Celebrating ASEEES: Reflections on the 2010s». NewsNet: News of the Association for Slavic, East European, and Eurasian studies, vol. 57, no. 5, 2018, pp.10-11.

Joyce, Aimee Edith. Border Landscapes: Religion, Space and Movement on the Polish-Belarusian Frontier. PhD dissertation. University of London, Goldsmiths' College, ProQuest Dissertations Publishing, 2014.

Koerber, Jeffrey P. Born in the Borderlands: Jewish Youth and Their Response to Oppression and Genocide, 1933-1948. PhD dissertation. Clark University, ProQuest Dissertations Publishing, 2015.

Kokobobo, Ani. «What's in a Name? Are We Slavic, East European, Eurasian, or All of the Above?». NewsNet: News of the Association for Slavic, East European, and Eurasian studies, vol. 60, no. 4, 2020, 17-18.

Men'kovskii, Viacheslav I. «Anglo-amerikanskaia rossica i sovietica na rubezhe XX-XXI vv.» Pracy gistarychnaga fakul'teta: navuk. zb. BDU, 2006, vyp. 6, ss. 243-255 [Меньковский, Вячеслав И. «Англо-американская россика и советика на рубеже XXХХІ вв.» Прачы гістарычнага факультэта: навук. зб. Мінск: БДУ, 2006, вып.1, cc. 243-255].

Mickiewicz, Ellen. «Celebrating ASEEES: Reflections on the 1980s». NewsNet: News of the Association for Slavic, East European, and Eurasian studies, vol. 57, no. 5, 2018, pp. 1-3. 
Novikau, Aliaksandr. Environmental Discourses in Belarus: Issues and Ideologies. PhD dissertation. Northern Arizona University, ProQuest Dissertations Publishing, 2017.

Park, Linda. «2011 Executive Director's Report». NewsNet: News of the Association for Slavic, East European, and Eurasian studies, vol. 52, no. 1, 2012, pp. 17-18.

Park, Linda. «2019 Executive Director Report». NewsNet: News of the Association for Slavic, East European, and Eurasian studies, vol. 60, no. 1, 2020, pp. 7-10.

Patyk, Lynn Ellen. Written in Blood: Revolutionary Terrorism and Russian Literary Culture, 1861-1881. University of Wisconsin Press, 2017.

Rosenberg, William. «Celebrating ASEEES: Reflections on the 2000s». NewsNet: News of the Association for Slavic, East European, and Eurasian studies, vol. 57, no. 5, 2018, pp. 8-9.

Thurston, Patricia K. «Doctoral Dissertations on Russia, the Soviet Union, Central Asia, and Eastern Europe Accepted by Universities in the United States and Canada, 1999». Slavic Review, vol. 59, no. 4, 2000, pp. 947-958.

Thurston, Patricia K. «Doctoral Dissertations on Russia, the Soviet Union, Central Asia, and Eastern Europe Accepted by Universities in the United States and Canada, 2000». Slavic Review, vol. 60, no. 4, 2001, pp. 897-908.

Thurston, Patricia K. «Doctoral Dissertations on Russia, the Soviet Union, Central Asia, and Eastern Europe Accepted by Universities in the United States and Canada, 2005». Slavic Review, vol. 65, no. 4, 2006, pp. 861-879.

Thurston, Patricia K. «Doctoral Dissertations on Russia, the Soviet Union, Central Asia, and Eastern Europe Accepted by Universities in the United States and Canada, 2013». Slavic review, vol. 73, no. 4, 2014, pp. 970-985.

Walker G. «Doctoral Research in Russian and East European Studies: Trends and Realities from the UTREES Database.» Modern Humanities Research Association, 2016, www.mhra. org.uk/pdf/utrees-paper.pdf. Accessed 12 Dec. 2020.

\section{ROSJOZNAWSTWO I STUDIA WSCHODNIE PO ZAKOŃCZENIU ZIMNEJ WOJNY. NOWE OBLICZE DYSCYPLINY}

\section{Streszczenie}

Artykuł ukazuje rozwój rosjoznawstwa i studiów wschodnich (REES) w USA i Wielkiej Brytanii po zakończeniu zimnej wojny. Prócz zmian organizacyjnych i strukturalnych, jakie zaszły w tych dyscyplinach, zwrócono także szczególną uwagę na nowe kierunki i trendy w badaniach nad Wschodem, uwzględniając białorutenistykę jako studium przypadku. Badania na tym polu rozpoczęły się latach 90 . a od roku 2000 przeżywają rozkwit. Badaczy interesuje przede wszystkim historia kraju, politologia, antropologia i literaturoznawstwo. Powstawanie międzynarodowej społeczności badaczy pozwala Autorce artykułu sformułować wniosek, że dyscyplina, która miała wcześniej wyraźnie wschodni charakter, dziś zyskuje zasięg globalny.

Słowa kluczowe: Rosja i studia wschodnie; studia regionalne; ASEEES; statystyka; prace doktorskie; Białoruś. 


\section{RUSSIAN AND EAST EUROPEAN STUDIES AFTER THE END OF THE COLD WAR: A NEW FACE OF THE FIELD}

\section{Su m m a ry}

The paper deals with the new developments in the field of Russian and East European studies (REES) after the end of the Cold war, with the focus on the U.S. and Great Britain. Along with organizational and structural changes in the field special attention is devoted to new subjects and trends in the study of the region, with Belarus as a case study. Research in this field began in the $90 \mathrm{~s}$ and has been booming since the 2000s. Researchers are primarily interested in the history of the country, political science, anthropology, and literary studies. The formation of an international community of researchers allows us to conclude that previously "Western" discipline of REES is gaining a global character.

Keywords: Russian and East European Studies; area studies; ASEEES; statistics; doctoral dissertations; Belarus 